Articles

Winter 2006

\title{
Reinventing PowerPoint: A New Look at an Old Tool
}

Mark J. Hofer

College of William and Mary

Robb Ponton

Williamsburg-James City County Schools

Kathleen Owings Swan

University of Kentucky

Follow this and additional works at: https://scholarworks.wm.edu/articles

Part of the Curriculum and Instruction Commons

\section{Recommended Citation}

Hofer, Mark J.; Ponton, Robb; and Owings Swan, Kathleen, "Reinventing PowerPoint: A New Look at an Old Tool" (2006). Articles. 38.

https://scholarworks.wm.edu/articles/38

This Article is brought to you for free and open access by W\&M ScholarWorks. It has been accepted for inclusion in Articles by an authorized administrator of W\&M ScholarWorks. For more information, please contact scholarworks@wm.edu. 


\title{
Technology Feature
}

Kathleen Owings Swan \& Mark Hofer, Feature Editors

\section{Reinventing PowerPoint: A New Look at an Old Tool}

\author{
Mark Hofer \\ College of William \& Mary \\ Robb Ponton \\ Williamsburg James City County Schools \\ Kathleen Swan \\ University of Kentucky
}

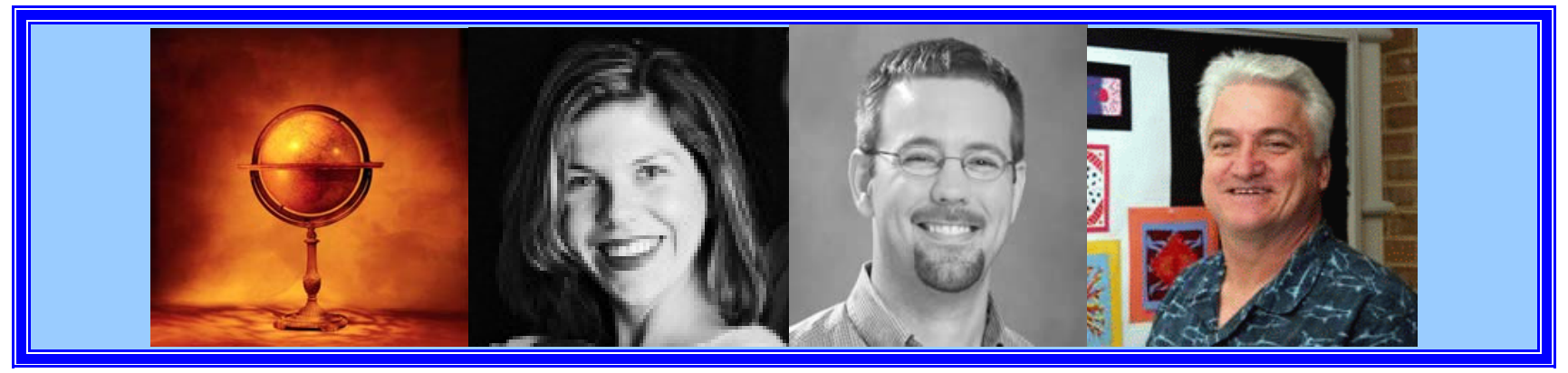

\begin{abstract}
Microsoft PowerPoint is a powerful, yet often underutilized, orchestration tool for learning. While its most common use may be no more powerful or effective than an overhead projector, the multimedia capabilities of the software open up powerful means to connect with diverse learners in the classroom. In this piece, we explore how PowerPoint can be used in ways that connect with Universal Design for Learning principles and make teacher and student presentations more engaging and effective. We offer several concrete examples of "thinking outside the slide" to leverage the unique potential of PowerPoint in the classroom.
\end{abstract}

Nicely constructed PowerPoint....I particularly liked the photographs of women in war as well as the quotes from the time period.

Sam has developed a range of very good PowerPoint presentations to display pictures of geographic landscapes and processes.

In the lesson, I observed Mr. Smith make excellent use of technology ( $L C D$ projector and PowerPoint software) to present a well-composed montage of 1970's musical styles. 
Mr. Jones frequently uses PowerPoint to introduce topics. In this lesson, after introducing the concept of globalization and making a connection to the students' real lives, he had them conduct their own research (via internet) about either a company or a country that made a product that the student owned and then create a short presentation using the same software.

Today's "Jeopardy" game was filled with sound effects and visuals. The PowerPoint engaged students and also helped address the learning needs of students who are not just auditory learners.

-excerpts of observation feedback for New Teachers in Kentucky, Open Portfolio

As teacher educators, many of us are tasked with assessing student teachers in their use of technology. The majority of states have adopted the National Educational Technology Standards for Teachers (NETS-T), and as a result, integrating technology has become one of the criteria in which novice teachers are judged to be proficient and ultimately, certified. The NETS-T standards have also been incorporated into the National Council for Accreditation of Teacher Education (NCATE) standards for teacher preparation programs. This emphasis on technology integration at the in-service and pre-service level places pressure on educators to effectively incorporate technology in their teaching. Technology integration, of course, can take many forms. After reviewing approximately 200 in-service and pre-service teacher evaluations in preparation for this article, however, we found almost 90 percent of the teachers being evaluated used the near-ubiquitous Microsoft PowerPoint presentation software to meet the technology standard. What makes a number of these observations unique, however, is that the novice teachers highlighted here are not just using presentation software to lecture bell-to-bell. Pulled from several teacher evaluations, the quotes above demonstrate that these student teachers are reinventing PowerPoint from traditional methods where students are often lulled to sleep by bullet point after bullet point of text to a medium in which primary sources could be displayed, coordinated, and projected and as a mechanism for formative and summative assessment. While some may argue that PowerPoint is Evil (Tufte, 2003) in that the software potentially reduces complex ideas into overly simplistic factoids; like it or not, teachers are using it (Swan \& Hicks, in press, Friedman, 2006, etc). Because of this, we felt it necessary to capitalize on the inspired uses of the software, provide a framework for combating its evil tendencies and supply examples of exemplars in the field.

\section{A Framework for Use: Universal Design for Learning}

Rather than thinking of the software as a digital overhead projector, PowerPoint is actually a powerful instructional orchestration tool that can enable a teacher to effectively incorporate many elements to meet the needs of diverse learners. One way to re-vision use of PowerPoint is to consider the principles of Universal Design for Learning (UDL) offered by the Center for Applied Special Technology (CAST). The core tenet of UDL is to construct instructional materials and strategies to make learning and student expression of understanding accessible to learners with varying learning preferences, obstacles, and styles (Center for Applied 
Special Technology, n.d.). Just as architects who practice Universal Design employ features in their design of public buildings to make them universally accessible to all people regardless of physical limitations, proponents of UDL advocate the design of instructional strategies and materials to appeal to many different types of learners.

In more than two decades of brain research, CAST suggests that learning occurs in three distinct but interconnected neural networks in the brain. The Recognition Network supports the learning of various types of information, including facts, concepts, and understandings. The Strategic Network focuses on problem solving, processes, and procedural learning. The Affective Network centers on student engagement and motivation for learning. In order to attend to these three learning networks, Rose, Meyer, and Hitchcock (2005) identify three principles of UDL:

1. To support recognition learning, provide multiple, flexible methods of presentation;

2. To support strategic learning, provide multiple, flexible methods of expression and apprenticeship; and

3. To support affective learning, provide multiple, flexible options for engagement. (p. 25)

Universal Design for Learning (UDL) is “a blueprint for creating flexible goals, methods, materials, and assessments that accommodate learner differences...it is meant to underscore the need for multiple approaches to meet the needs of diverse learners” (Center for Applied Special Technology, n.d.).

One of the fundamental concerns of critics of PowerPoint is that it often is used as a fancy overhead projector with over-reliance on unnecessary clipart, overcrowded text, and distracting sounds and animation. Many users employ the notion that more is better and need a crash course in graphic design rooted in educational principles. This may explain the increasing disdain for PowerPoint among many educational technologists and experienced classroom teachers alike. This critique, however, confuses tool and method. What makes PowerPoint effective or not is how it is used in the teaching and learning process. Below, we offer a new view of PowerPoint and how it may be implemented more effectively in the classroom.

\section{Thinking Outside the Slide}

If you are not an experienced user of PowerPoint, it is easy to think that the only way to use the software is for traditional, didactic instruction. Upon opening the software, you are introduced with title slides and bulleted lists. Features such as non-linear navigation, purposeful animation, and multimedia options are often overshadowed by basic functionality and take some time and work to unearth. In the following sections, we hope to illustrate some unconventional methods of the software usage including the ability to use multiple forms of media, multiple ways to access content, multiple ways to publish materials, and the inherent flexibility of the designer to tailor the materials to different learning needs. 


\section{Multiple Forms of Media}

Despite some limitations with specific files types (e.g., the popular .aac music files used in Apple's iTunes Music Store), a wide range of media types can be incorporated into PowerPoint presentations. Text, graphics, photographic images, sound clips, music, video, and animations can all be embedded in PowerPoint to present information, concepts, and processes in a variety of ways (e.g., teaching students about warfare in Ancient Greece). In addition to the typical bullet-point text notes and images found in textbooks or copied onto overhead transparencies, teachers can also incorporate diagrams, Flash animations, illustrations, and video excerpts from biography programs to illustrate the phalanx formation in action. Although arranging these types of media supports independently in the classroom might be tedious, timeconsuming, and require a hefty power strip to support the overhead projector, TV with VCR, document camera, etc., aside from the time taken to gather these multimedia resources, it takes very little extra effort to incorporate all these elements into a typical PowerPoint presentation.

One presentation created for a 9th grade World Civilization class on Central America utilizes a variety of media types. The presentation was designed for individual student exploration, allowing students the opportunity to explore the content in their own way at their own pace. Using both English and Spanish language video clips from Discover Education's unitedstreaming online database of video (see additional notes re: screenshot and access instructions), she was able to provide short, focused video content that extended the content presentation beyond what could be accomplished without the video. For example, in one clip from unitedstreaming, students are introduced to indigenous peoples in Central America and their unique heritage. In addition to the use of video, she also incorporated music and images from popular culture to engage the students and tie the content to life outside school. She incorporated animations on a map of Central America to help focus student attention on facts about the different countries while simultaneously highlighting their geographic location. She also incorporated multiple optional activities throughout in the form of hyperlinks to external websites including the CIA World Fact Book for exhaustive information on each of the countries as well as links to newspaper articles and other relevant sites. In using multiple forms of media, she not only created multiple entry points into the essential content, but she also fashioned ways to draw students in and springboards for extending their learning beyond the required content.

\section{Multiple Ways to Access Content}

In addition to the typical linear use of PowerPoint, the creator can utilize text- or imagebased hyperlinks or action buttons to explore the content in a variety of ways. Hyperlinks to either slides or external websites can be included for students who either require more information on a given topic or extension activities can be incorporated in the base version of a presentation. A presentation can be set up as an historical narrative in the choose your own adventure format, a "Jeopardy" game board, a clickable map, a virtual newspaper front page, or any other number of ways for students to enter into and explore the content of a presentation.

A group of teachers created a versatile presentation to introduce middle school students to new vocabulary words. The presentation includes text, images paired with the words, audio narration, example uses of the words in sentences and short video clips, rollovers for definitions, and an interactive quiz to help the students gauge their mastery of the words as well as other means of engaging with the content. While the presentation can be used for whole-class work, it 
is designed with enough options, embedded media, and extension activities for students to continue their learning outside of class. This presentation could also serve as a model for teams of students who could be assigned to create a presentation from an assigned chapter in their textbook. The team of students would then be responsible for presenting the content to their peers in a way that they will understand it, employing UDL principles. A rubric will inform students of certain requirements but the communication of the content is up to the teams.

\section{Multiple Publishing Options}

Once a teacher has created a PowerPoint presentation, she has many options for alternative ways to publish the content. In addition to presenting the material in the front of the classroom through some type of projection device, the teacher may save the presentation (including animations and transitions) on the web as high-quality handouts in the form of a kiosk presentation to be explored by students independently or in small groups or as a narrated movie file. Again, because of the flexible nature of digital media and the software, these alternative products require little extra time and effort to create. For example, saving the presentation for the web requires the teacher only to select Save as Web Page under the File menu. Even creating a narrated movie version of a presentation only requires the teacher to plug in an inexpensive microphone to the computer and select Record Narration under the Slideshow menu. The teacher then presents the material into the microphone, and the animation clicks, timing, and narration are all saved as a part of the file. When saved as a PowerPoint Show file, once opened, the narrated movie begins automatically.

In partnership with her cooperating teacher, one preservice teacher created a kiosk presentation on geographic features of Europe for her $10^{\text {th }}$ grade World Civilizations class to enable students to explore how different geographic features including mountains, rivers, and natural resources impact development, population, and politics. In utilizing multiple media options (e.g., videos, illustrations, graphs, text, etc.) and non-linear format discussed above, this presentation also permitted easy reformatting to publish the content in many different ways. For example, because of the focused and limited text on the slides and the structured content, she would be able to (and did) use the presentation for whole class instruction. By saving the presentation and accompanying media files in her web space, the pre-service teacher was able to make the presentation available for absent students and those that needed extra reinforcement to browse the content from outside of class. She also was able to easily create handouts that included the text, graphics, and images from the File, Print Handouts option within PowerPoint for those students who required teacher-provided notes according to their individual education plans (IEP). She would also be able to copy and paste the charts and graphics into a Word document to use in a review sheet and/or an assessment. The creation of this single, rich presentation enabled multiple publishing options (and student entry points) with little extra effort on the part of the teacher. 


\section{Modifying Media Files}

One difference in using digital images or video clips as a part of a PowerPoint presentation in contrast to their analog counterparts is the flexibility of the designer to modify the media in a number of ways to meet specific instructional needs. A digital image, for example can be cropped, resized, or brightened to focus on or emphasize key elements within the image using the PowerPoint picture toolbar. Sounds or speech can be recorded and embedded on a slide using the built-in sound recorder. Digital video clips like those downloaded from unitedstreaming or from a digital camcorder can be cropped using either Windows Moviemaker or Apple iMovie which are included in the Windows XP or Apple OS operating systems. Even PowerPoint animations, which can sometimes serve no discernable purpose or even distract from the content, can be customized to a great degree to control the order, speed, direction, and intensity of text, image, video, or sound options entering the presentation. For example, a $6^{\text {th }}$ grade social studies teacher created an animated map of the battlefield at Gettysburg, graphically illustrating troop movements that ultimately determined the outcome of the battle.

\section{Opportunities for Student-Created Multimedia}

In addition to the teacher-directed examples noted above, there is also powerful potential to challenge students to create their own multimedia presentations incorporating various forms of digital media to convey their understanding of a topic. This approach shifts the students from consumer to producer of media (Hobbs, 1998) and encourages students "learning with" the technology (Reeves, 1998). With a frame of reference and targeted instruction on the finer points of working with digital media (i.e., inserting a video clip, cropping an image, etc.), students are highly capable of creating PowerPoint presentations similar to those noted above. The emergence of rich online digital archives (Hofer, 2005), like the Library of Congress website, provides students with the necessary raw material required. A social studies teacher might challenge students to develop a "virtual exhibit" of a time period in which students assemble images and video clips with appropriate "signage" in an exploratory format, or using green screen backdrops, place themselves into actual Civil war photos. Students could also use the narration feature to record a narration of their slides effectively creating a Ken Burns style documentary film.

Assessing these kinds of projects does provide a challenge, however. Because there are so many components to a multimedia project, the teacher must carefully weigh what counts and for how much. For example, the creation of a multimedia book analysis PowerPoint includes reading comprehension and analysis, background research, writing, selection of appropriate media, layout, and design, etc. Utilizing a scoring rubric, the teacher should carefully determine what elements of the projects are worth, effectively focusing students on the elements most closely connected with the curriculum content and goals. If provided to the students in advance of beginning the project, the students will be aware of what is expected and are thus more able to meet the standards outlined by the teacher. Rubric generator tools like Rubistar can be helpful in both the development and creation of a scoring rubric for a variety of types of projects. 


\section{Conclusion}

Teachers are working harder and harder to simultaneously integrate technology into instruction and improve student learning outcomes. As former teachers, we know this is no easy task. Technology can often eclipse social studies instruction by taking additional time and diverting students from the content objectives (Hofer \& Swan, 2005). Arguably, PowerPoint offers a unique opportunity to harness the power of digital media in manageable ways for classroom teachers to enable them to more fully engage their students in their study of the social studies. This "low threshold, high ceiling" nature of the software may help to both spark the imagination of both teachers and students while still addressing core content and processes in the classroom.

While mastering the new skills required to incorporate UDL principles into PowerPoint presentations is relatively easy to do; for a summary of these principles and requisite skills with the software, see the following website: Leveraging PowerPoint to UDL Instruction), identifying "promising practices" in using PowerPoint in this way is more emergent. Both experimental and action research on these applications of PowerPoint in education would help inform teachers and teacher educators where to best focus our time and energy. This requires educators to put aside their PowerPoint bias and creatively explore how to leverage the nascent potential of the software to support teaching and learning.

\section{$\underline{\text { Additional notes about unitedstreaming }}$}

The unitedstreaming Digital Video Library, a division of Discovery Education, is a subscription-based web database of educational videos which can be viewed on the web or downloaded for use in a variety of ways, including incorporation into PowerPoint. Videos are organized by content area, content topic, grade level, and curriculum standard. Using the intuitive and effective search feature yields descriptions of the videos matching the search request including the total running time of the video and any ancillary materials (lesson guides, handouts, etc.). Perhaps the most useful feature for busy classroom teachers is that all the videos can be viewed or downloaded either in their entirety or as short clips. So, for example, rather than downloading the entire 55-minute video of American History: The Civil War: A Nation Divided, the teacher can select to download one of thirteen clips from the video ranging from one to five minutes. These focused, limited clips are often perfect for incorporation into a presentation-providing only the portion relevant to the discussion at hand. Unitedstreaming can be found online at http://www.unitedstreaming.com. 


\section{Bibliography}

Center for Applied Special Technology (CAST), (n.d.). Universal design for learning. Retrieved July 10, 2006, from http://www.cast.org

Friedman, A.M. (2006). World history teachers' use of digital primary sources: The effect of training. Theory and Research in Social Education, 34, 124-141.

Hobbs, R. (1998). Literacy for the information age. In J. Flood, S.B. Heath, \& D. Lapp (Eds.), Handbook of research on teaching literacy through the communicative and visual arts (pp. 7-14). New York: Simon \& Schuster Macmillan.

Hofer, M. (2005). Web-based digital content: Promise and practice. Threshold: Exploring the Future of Education, 3(3), 12-15.

Hofer, M., \& Owings-Swan, K. (2005). Digital moviemaking-the harmonization of technology, pedagogy, and content. International Journal of Technology in Teaching and Learning, 1(2), 102-110.

Reeves, T.C. (1998). The impact of media and technology in schools: A research report prepared for The Bertelsmann Foundation. Retrieved January 28, 2002, from http://www.athensacademy.org/instruct/media_tech/reeves0.html

Rose, D.H., Meyer, A., \& Hitchcock, C. (2005). The universally designed classroom: Accessible curriculum and digital technologies. Cambridge, MA: Harvard Education Press.

Swan, K. \& Hicks, D. (in press) Through the democratic lens: The role of purpose In leveraging technology to support historical thinking in the social studies classroom. The International Journal of Social Studies Education.

Tufte, E. (2003). The cognitive style of PowerPoint. Cheshire, CT: Graphics Press. 